\title{
Crenças de autoeficácia e estratégias de aprendizagem: um estudo de caso dos ingressantes no curso de Licenciatura em Física
}

\author{
Diego Marceli Rocha
}

Universidade Federal de Campina Grande, Centro de Formação de Professores, Unidade Acadêmica de Ciências Exatas e da Natureza, Rua Sérgio Moreira de Figueiredo, Casas Populares 58900-000, Cajazeiras, Paraíba, Brasil. E-mail: diego.rocha@ufcg.edu.br
Rocha D.M. (2020) Crenças de autoeficácia e estratégias de aprendizagem: um estudo de caso dos ingressantes no curso de Licenciatura em Física. Pesquisa e Ensino em Ciências Exatas e da Natureza, 4: e1462. http://dx.doi.org/10.29215/pecen.v4i0.1462

Editor acadêmico: Gustavo Lopes Ferreira. Recebido: 02 junho 2020. Aceito: 22 julho 2020. Publicado: 24 julho 2020.

Resumo: A etapa de ingresso dos estudantes nos cursos de licenciatura é uma fase de relevante análise a respeito dos processos que gerenciam as estratégias de aprendizagem dos futuros professores. A fim de compreendermos os fatores que se relacionam com as estratégias de aprendizagem dos alunos e com seu desempenho acadêmico, é que escolhemos as crenças de autoeficácia, propostas por Albert Bandura (1986), como constructo teórico para estudarmos tais relações, logo na etapa de ingresso dos estudantes no curso de licenciatura em Física. Assim, por meio de uma pesquisa qualitativa, em um estudo de caso, realizamos entrevistas, em momentos distintos do ingresso, de três alunos do curso de licenciatura em Física do Centro de Formação de Professores da Universidade Federal de Campina Grande (CFP/UFCG). O estudo revelou um incremento no nível de autoeficácia desses estudantes na passagem do primeiro para o segundo período do curso. Esse aumento em seus níveis de autoeficácia resultou em diferentes estratégias de aprendizagem que, por sua vez, possibilitaram um melhor desempenho acadêmico nessa fase do curso de graduação.

Palavras chave: Autoeficácia, Licenciatura em Física, desempenho acadêmico, estratégias de aprendizagem.

Self-efficacy beliefs and learning strategies: a case study of members in the Physics Graduation course

Abstract: The stage of entry of students in undergraduate courses is a phase of important analysis regarding the processes that manage the learning strategies of future teachers. In order to understand the factors that relate to the students' learning strategies and their academic performance, we choose the selfefficacy beliefs, proposed by Albert Bandura (1986), as a theoretical construct to study such relationships, right at the stage of entry of students in the Physics Degree course.Thus, through qualitative research, in a case study, we conducted interviews, at different times of admission, of three students in the Physics Degree course at the Teacher Training Center at the Federal University of Campina Grande (CFP/UFCG). The study revealed an increase in the level of self-efficacy of these students in the transition from the first to the second period of the course. This increase in their levels of self-efficacy resulted in different learning strategies that, in turn, enabled better academic performance in this phase of the undergraduate course.

Key words: Self-efficacy, Degree in Physics, academic performance, learning strategies.

\section{Introdução}

A carreira docente é um processo de formação contínua que tem seu início logo no ingressar da Educação Superior. Para alguns sujeitos, a escolha pela profissão docente pode ser 
respaldada por diferentes situações que, não necessariamente, estão ligadas a essa etapa do ensino. Ou seja, não é de se estranhar aqueles indivíduos que optaram por ser tornar professor a partir de influências familiares, ou de seus professores da Educação Básica, e até mesmo pelos saberes estudados durante essa fase. Todavia, é no Ensino Superior que a construção de uma identidade docente é fundamentada, a partir da construção dos saberes docentes e também dos saberes específicos das disciplinas em estudo. Dessa forma, os primeiros contatos com o ambiente universitário, as disciplinas dispostas pelo curso de licenciatura, as opções pela carreira docente e a perspectiva de formação profissional tornam esse momento de ingresso um período interessante de análise dos fatores associados às estratégias de aprendizagem e desempenho acadêmico dos estudantes.

Nesse estudo, em especial, estamos interessados em analisar como esses fatores se correlacionam com as crenças de autoeficácia (Bandura 1986) dos sujeitos ingressos em curso de licenciatura em Física. Para Bandura (1986: 391) as crenças de autoeficácia são definidas como: "julgamentos das pessoas sobre suas capacidades para organizar e executar cursos de ação necessários para alcançar certo grau de performance".

De acordo com Silva et al. (2011), os níveis de autoeficácia dos professores com formação em Física estão diretamente associados a seu estado motivacional para lecionar a respeito dessa disciplina. Rocha \& Ricardo (2013) revelam que os níveis de autoeficácia dos docentes possuem interessante correlação com a proposição de atividades de inovação curricular na área de Física.

Simões et al. (2014) já apontavam para o fato de as crenças de autoeficácia dos alunos, a respeito da disciplina da Física, ainda na fase da Educação Básica, possuírem relativa influência na escolha dos sujeitos pela carreira docente em Física. Restuboget et al. (2010) concordam que os níveis de autoeficácia dos estudantes estabelecem relação com os propósitos para escolha de suas carreiras. Além disso, Simões et al. (2016) revelam que a escolha pela carreira dos ingressantes em um curso de licenciatura em Física está ligada a uma série de fatores entre eles, as crenças de autoeficácia a respeito da docência e das atividades de Física.

Vale destacar que as crenças de autoeficácia estão relacionadas com as capacidades perceptivas de julgamento dos indivíduos a respeito de suas habilidades. Para Bandura (1997), elas são a base para a motivação humana, o gerenciamento do bem-estar e a promoção das realizações pessoais. Segundo Pajares \& Olaz (2008: 101), "isto porque, a menos que acreditem que suas ações possam produzir os resultados que desejam, as pessoas terão pouco incentivo para agir ou perseverar frente a dificuldades".

As crenças de autoeficácia influenciam as escolhas dos indivíduos, fazendo com que os mesmos optem por realizar tarefas em que se sintam mais confiantes e competentes, como também evitem aquelas em que não se sintam dessa forma. Além disso, determinam o grau de esforço e persistência que um sujeito irá aplicar na execução de uma atividade, em vista dos obstáculos que advirão dessa situação. E ainda, influenciam também os padrões de pensamento e reações emocionais dos indivíduos promovendo, por vezes, sentimentos de serenidade (alto nível de autoeficácia) ou de estresse e/ou depressão (baixo nível de autoeficácia) na abordagem de determinadas tarefas (Pajares 1996).

Tais crenças estão fortemente configuradas com o comportamento humano, possibilitando, muitas vezes, a determinação de ações por meio do conhecimento de suas crenças em suas capacidades. Esse fato nos permite compreender como as pessoas se comportam em vista de suas capacidades reais de executar determinada tarefa, onde, em muitos casos, as pessoas são capazes o suficiente para realizar determinado curso de ação, mas não o fazem em vista de uma fraca crença de autoeficácia. Ou ainda, deparamo-nos com casos em que as pessoas não são tão qualificadas para a tarefa, mas se propõem a realizá-la por deterem um forte senso de autoeficácia (Pajares \& Olaz 2008).

Assim, muito mais do que deter as habilidades e os conhecimentos para a realização de uma determinada ação, o indivíduo deveria possuir as crenças de autoeficácia em um nível suficiente para executar a tarefa. Todavia, é importante salientar que as crenças de autoeficácia 
não são suficientes para produzir o sucesso na ação de um sujeito sem que esse possua alguma habilidade ou conhecimento para realizar a ação.

A partir da importância dada às crenças de autoeficácia para o entendimento do comportamento humano, diversas linhas de pesquisas surgiram nos mais diferentes campos, tais como: educação, promoção da saúde, prevenção de doenças, disfunções clínicas, realizações atléticas, funcionamento organizacional, eficácia de sistemas sociais e políticos (Bandura 2005).

$\mathrm{Na}$ perspectiva do Ensino Superior, Guerreiro (2007) revelou que as crenças de autoeficácia são um importante fator para a permanência e o sucesso nesse nível educacional. Além disso, o estudo constatou um decréscimo no nível de autoeficácia dos ingressantes ao longo do primeiro ano em diversos cursos de graduação. Chemers et al. (2001), constataram que as crenças de autoeficácia de estudantes do primeiro ano do Ensino Superior se relacionavam diretamente com o seu desempenho acadêmico e com suas expectativas acadêmicas. Os autores revelam que estudantes universitários que demonstram crenças de autoeficácia em nível mais elevado persistem no trabalho acadêmico, fazem uso de estratégias de aprendizagem para a resolução de problemas e são mais eficientes em gerir o ambiente de aprendizagem.

Zajacova et al. (2005) concluíram que as crenças de autoeficácia dos estudantes possuem um efeito positivo sobre as notas dos alunos ingressantes no Ensino Superior. Gore (2006) revela que as crenças de autoeficácia dos estudantes universitários são interessantes preditores de seus desempenhos acadêmicos, bem como de sua persistência para a realização de determinadas tarefas. Elias \& MacDonald (2007) corroboram com as conclusões apresentadas por Wood \& Bandura (1989) ao revelar que os níveis de autoeficácia acadêmica dos estudantes universitários se mostraram um fator mais preditivo do desempenho acadêmico dos estudantes do que as suas experiências vivenciadas.

Lynch (2010) revelou que as crenças de autoeficácia dos estudantes de Física se correlacionam com suas crenças motivacionais, suas estratégias de aprendizagem e seu desempenho acadêmico. $\mathrm{O}$ estudo revelou ainda, uma diferença de níveis de autoeficácia a partir do gênero dos participantes. Para Nissen (2016) a diferença no grau de autoeficácia com relação ao gênero dos alunos ingressantes no curso de Física está associada à iniquidade dos cursos de graduação. De acordo com Lindstrom \& Sharma (2011) tal diferença não resulta em desempenhos acadêmicos distintos, além disso, o estudo revela um incremento nos níveis de autoeficácia dos estudantes do gênero feminino logo no segundo semestre do curso de Física.

Heidemann et al. (2020) apresentam uma disciplina introdutória para alunos de licenciatura em Física, com o intuito de elevar os níveis de autoeficácia dos estudantes ingressantes, a partir da utilização de metodologias ativas. $\mathrm{O}$ estudo revelou que a disciplina proporcionou uma maior motivação dos estudantes nessa fase inicial, como também, contribuiu para a construção de uma identidade docente e maior compreensão conceitual dos saberes físicos. Nessa direção, Carberry et al. (2010) destacam que o reconhecimento dos níveis de autoeficácia dos estudantes, durante o período da graduação é fundamental para a escolha das ferramentas didático-metodológicas para a melhoria de sua aprendizagem.

As crenças de autoeficácia dos sujeitos são interessantes preditores do comportamento humano (Pajares \& Olaz 2008). Nesse sentido, estudos já revelaram relações entre o desempenho acadêmico e os níveis de crenças de autoeficácia dos estudantes nos mais diferentes cursos de graduação. Ademais, tais estudos corroboram para o conhecimento das mais diversas estratégias de aprendizagem, a partir da fundamentação das crenças de autoeficácia dos sujeitos.

Desse modo, a partir de um estudo de caso, analisamos as relações entre as crenças de autoeficácia dos alunos ingressantes no curso de licenciatura em Física do Centro de Formação de Professores da Universidade Federal de Campina Grande (CFP/UFCG) no ano de 2019, com seu desempenho acadêmico. Visamos analisar os comportamentos desses alunos, suas primeiras impressões a respeito do curso, bem como, revelar suas estratégias de aprendizagem, em vista da constituição de seus níveis de autoeficácia. A fim de aprofundarmos os estudos, a respeito das crenças de autoeficácia e as estratégias de aprendizagem dos alunos, realizamos duas entrevistas em períodos diferentes do ingresso. Dessa forma, pudemos reconhecer como os níveis de autoeficácia dos sujeitos atuam sobre seu desempenho acadêmico ${ }^{1}$. 


\section{Metodologia}

Para compreendermos como as crenças de autoeficácia atuam no comportamento dos alunos ingressantes no curso de licenciatura em Física do CFP/UFCG a respeito de suas estratégias de aprendizagem e desempenho acadêmico optamos por fazer uso de uma pesquisa de natureza qualitativa. De acordo com Schunk (1991) e Pajares (1992), apesar de um elevado número de trabalhos de natureza quantitativa a respeito das crenças de autoeficácia dos indivíduos apresentarem

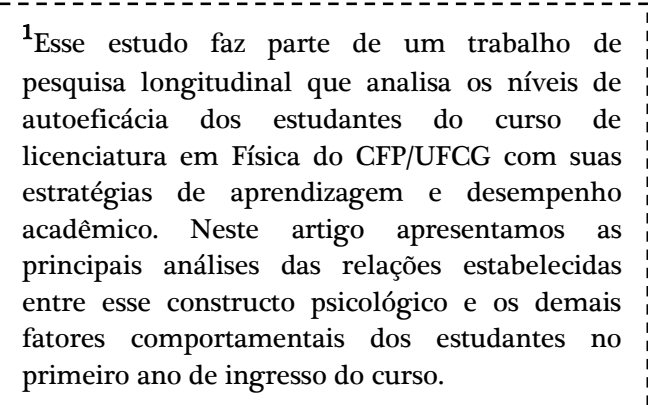

${ }^{1}$ Esse estudo faz parte de um trabalho de pesquisa longitudinal que analisa os níveis de autoeficácia dos estudantes do curso de licenciatura em Física do CFP/UFCG com suas estratégias de aprendizagem e desempenho acadêmico. Neste artigo apresentamos as principais análises das relações estabelecidas fatores comportamentais dos estudantes no primeiro ano de ingresso do curso.

interessantes análises e conclusões para essa área de pesquisa, a metodologia qualitativa como, por exemplo, estudos de casos são fundamentais para a obtenção de dados e análises adicionais a respeito das crenças de autoeficácia. Para Pajares (1996), a pesquisa de natureza qualitativa proporciona uma relevante contribuição para os estudos que se preocupam com as autocrenças dos sujeitos no contexto acadêmico.

Sendo assim, optamos pela escolha de uma pesquisa do tipo estudo de caso para analisarmos as crenças de autoeficácia dos alunos ingressantes no curso de licenciatura em Física do CFP/UFCG, em vista de aprofundarmos nossas discussões em contextos particulares aos sujeitos de pesquisa. Tal escolha é respaldada por Bandura (1997) que afirma que as crenças de autoeficácia devem ser analisadas a partir de julgamentos particularizados dos sujeitos, podendo variar em diferentes níveis de exigência, domínio de atividades e circunstâncias situacionais.

Assim, um conjunto de três alunos aceitou contribuir com o estudo em questão. Por meio de entrevistas semiestruturadas, no início do primeiro período e ao final do segundo período, buscamos analisar a influência de suas crenças de autoeficácia com relação ao seu desempenho acadêmico e suas estratégias de aprendizagem na fase inicial do curso de graduação.

Segundo Ludke \& André (1986), a grande vantagem da entrevista sobre as demais técnicas de coletas de dados é que esta permite a captação imediata e corrente da informação desejada, praticamente com qualquer tipo de informante e sobre os mais diversos tópicos. Para Minayo (2010), tal instrumento de coleta de dados possibilita ao entrevistado uma reflexão sobre sua realidade, evidenciando suas crenças, sentimentos, opiniões,

${ }^{2}$ As transcrições apresentadas na seção seguinte são literais. Alguns vícios de linguagem foram suprimidos para facilitar a leitura, sem, no entanto, alterar o conteúdo.

${ }^{3}$ Todo o processo metodológico de coleta de dados desse estudo foi submetido ao Comitê de Ética e Pesquisa, via plataforma Brasil, com Certificado de Apresentação para Apreciação Ética (CAAE), sob o número, 03798818.3.0000.5182 e aprovado pelo Parecer de Número 3.155.455.

${ }^{4}$ Denotaremos os alunos pelos codinomes: Sujeito A, Sujeito B e Sujeito C. Além disso, após cada codinome aparecerá um índice referente ao momento a que se atribui a sua fala. Por exemplo, Sujeito A.1, nesse caso temos a transcrição da entrevista do Sujeito A no primeiro período de entrevistas, já o índice A.2, refere-se à fala do Sujeito $\mathrm{A}$ no segundo período de entrevistas. comportamentos e projeções futuras. Dessa forma, os alunos foram convidados a participar dessa etapa de coleta de dados. Após a gravação das entrevistas, estas foram transcritas ${ }^{2}$, buscando analisar e interpretar as informações principais fornecidas pelos entrevistados ${ }^{3}$.

\section{Análise dos dados}

Nossa primeira preocupação antes de analisarmos a relação entre os níveis de autoeficácia dos sujeitos e seu desempenho acadêmico foi o de buscar compreender quais foram os fatores motivacionais que conduziram a escolha desses jovens até o curso de licenciatura em Física. Vejamos as primeiras afirmações apresentadas pelos sujeitos:

Eu não sei[...] Estudei um pouquinho, fiz o ENEM. A nota para entrar aqui não é tão alta e eu consegui entrar para Física. (SUJEITO A.1 $)^{4}$ 


\section{Autoeficácia e estratégias de aprendizagem}

Primeiro porque a pontuação estava muito alta[...] Bastante[...] Estava absurda para entrar, onde eu quero que é na UFCG de Campina Grande. E analisei e vi que dava para começar Física e mesmo que eu não termine Física, vai ser uma boa base. Caso, durante eu consiga, enquanto estiver estudando Física, ir para lá, vai ser uma boa base. (SUJEITO B.1)

De acordo com o Sistema de Seleção Unificada (Sisu) no ano de 2019 a nota de corte para seleção dos ingressantes no curso de licenciatura em Física do CFP/UFCG foi igual a 587.14. Durante a entrevista, o Sujeito B deixa claro que o seu intuito era o de cursar Engenharia Elétrica no campus de Campina Grande da referida Universidade. A fim de comparação, a nota de corte para esse curso, no período em questão, era de 707.14, valor relativamente superior aquele disposto para o curso de licenciatura em Física.

Dos extratos anteriores percebemos que a nota de corte, não tão elevada para adentrar o curso de licenciatura em Física, pode ser um dos fatores que levaram esses sujeitos a iniciar sua graduação. Todavia, os sujeitos deixam claro certa incerteza, no primeiro momento das entrevistas, de suas escolhas e desejo por outras carreiras como afirma o Sujeito B. Simões et al. (2014) demonstraram que as crenças de autoeficácia dos estudantes ingressos em um curso de licenciatura em Física estão diretamente relacionadas com suas motivações para a escolha de sua carreira acadêmica. Desse modo, podemos projetar que essa possível incerteza pode implicar de forma negativa nos níveis iniciais de autoeficácia dos alunos logo no seu primeiro ano da graduação.

Apesar da escolha pelo curso de licenciatura em Física se apresentar como uma possível segunda opção para os participantes do estudo, é interessante observar a existência de um tipo de relação dos sujeitos com os saberes pertencentes à Física:

É que nenhum outro curso se identifica comigo como a Física. Porque eu sempre tive uma facilidade muito grande com números e como eu falei, eu dou aula de reforço. No Ensino Médio dei aula de reforço de Física e Matemática[...] Mais por vocação[...] Eu me identifico mais com a Física, do que qualquer outra [graduação] daqui. Eu me identifico porque quando estava cursando Eletromecânica eu vi muita Física. Tive muitas disciplinas que tinham Física e sempre tive esse interesse. (SUJEITO B.1)

Porque eu estava em dúvida entre algumas matérias[...] Porque eu também gostava muito do professor de Física[...] Aí eu estava em dúvida entre Química ou Física, mas eu optei por Física[...] Porque eu preferi. Eu gosto na verdade das teorias e tal[...] Eu gosto disso sabe[...] Eu gosto do universo da Física, por exemplo, o espaço[...] Eu acho interessante isso aí[...] (SUJEITO C.1)

Porque eu gosto[...] Vem desde, eu acho, do fundamental[...] Já eu gostava de Matemática e do oitavo para o nono ano eu fui me interessando mais pela Ciência. No Ensino Médio eu tive certeza eu queria Física[...] Porque eu achei interessante a maneira como aplicava a Matemática[...] Eu também gostava[...] Me interessava um pouco por Astronomia[...] Acho que foi no nono ano[...] Ganhei o livro de minha tia e me interessei. Depois de um tempo eu fui conhecer a Física, no nono ano ainda. Achei interessante, porque usava Matemática e eu já tinha uma certa afinidade. Daí no Ensino Médio eu fui desenrolando mais[...] (SUJEITO A.1)

Do extrato da fala do Sujeito B fica evidente uma identificação com os saberes físicos, muito mais estruturada do que aquela estabelecida pelos saberes educacionais. Tal realidade, por vezes, é resultante da experiência do indivíduo enquanto aluno da Educação Básica. Para Simões et al. (2014) um senso de autoeficácia elevado proveniente da vivência dos sujeitos durante as aulas de Física, ainda na Educação Básica, permite aos sujeitos dar continuidade a seus estudos na área de Física em etapas posteriores. Assim, a escolha pelo curso de licenciatura em Física pode ser justificada pelo elevado nível de autoeficácia do sujeito traduzido em sua identificação com o saber físico em maior grau do que com os saberes educacionais. Contudo, veremos mais adiante que esse elevado senso de autoeficácia do Sujeito B, estabelecerá diferentes estratégias de 
aprendizagem, a partir, dos saberes tratados nas diferentes disciplinas do curso.

Além disso, um ponto importante apresentado nas falas anteriores, diz respeito à criação de estados afetivos com o saber físico. De acordo com Custódio (2007), a construção de vínculos afetivos com o conhecimento científico permite a garantia da sobrevivência aos mesmos fora do contexto escolar. Desse modo, percebemos que os sujeitos deixam transparecer um tipo de sentimento pelo saber físico, a partir das expressões, como: "Porque eu gosto"; "Eu gosto disso sabe". A construção desse vínculo afetivo com o saber, ou até mesmo com a figura docente, como retrata o Sujeito C, pode ter exercido certa influência na escolha desses indivíduos pelo curso e consequentemente influenciado seus níveis iniciais de autoeficácia. Para confirmar nossa hipótese de projeção de vínculo afetivo com o saber, apresentamos a fala do Sujeito A, após a conclusão do primeiro período do curso, quando indagamos se ela ainda gostava de Física. A resposta obtida segue:

Continuo gostando[...] Agora está um pouquinho acima[...] Eu gosto de Física, eu acho que estar aqui cursando Física[...] Eu sei lá[...] Eu me sinto mais próxima da Física. Está sendo uma experiência legal para mim. Diferente do ensino médio que era aquela coisa que só passava por cima. (SUJEITO A.2)

Percebamos que apesar de um novo cenário de estudo (Ensino Superior) onde, por vezes, as regras dispostas pelos diversos Contratos Didáticos (Brousseau 1986), ainda não estão claras aos sujeitos da relação didática, a questão do vínculo afetivo com o saber físico toma uma dimensão interessante que permite ao sujeito se aprofundar mais sobre ele, desenvolvendo uma ligação mais fortemente estruturada com o mesmo. Sendo assim, é interessante notar como essas expectativas apresentadas pelos sujeitos, a priori, conduzem suas reflexões a respeito da estrutura curricular e participação nas diversas disciplinas que tratam dos diferentes saberes no primeiro ano do curso de licenciatura. Dessa forma, apresentamos as primeiras impressões dos alunos a respeito do curso:

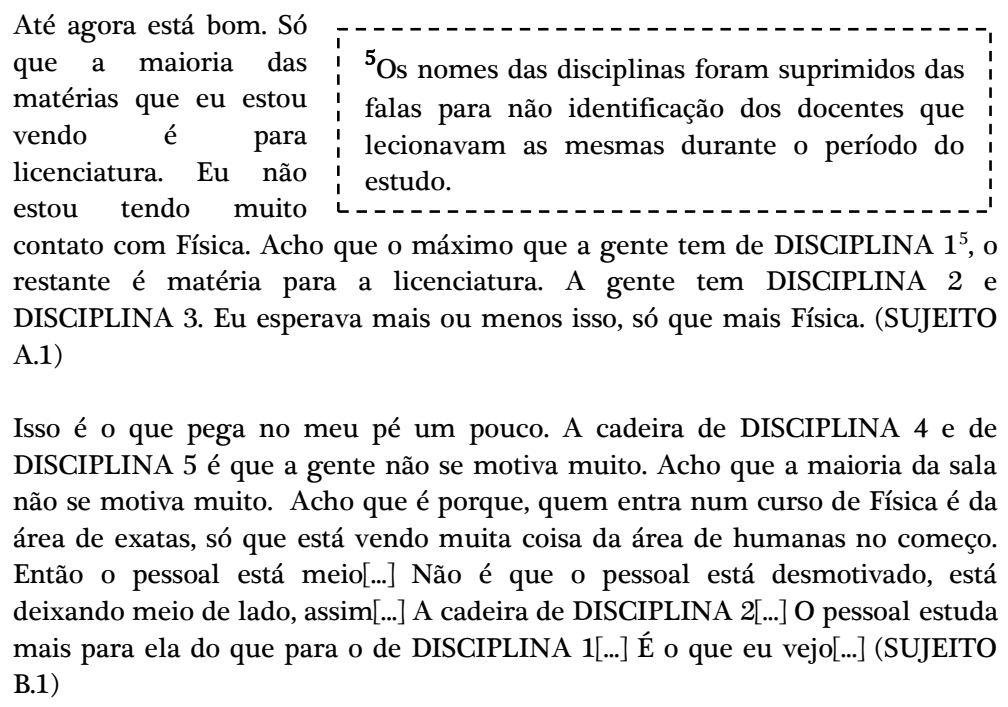

Isso é o que pega no meu pé um pouco. A cadeira de DISCIPLINA 4 e de DISCIPLINA 5 é que a gente não se motiva muito. Acho que a maioria da sala não se motiva muito. Acho que é porque, quem entra num curso de Física é da área de exatas, só que está vendo muita coisa da área de humanas no começo. Então o pessoal está meio[...] Não é que o pessoal está desmotivado, está deixando meio de lado, assim[...] A cadeira de DISCIPLINA 2[...] O pessoal estuda mais para ela do que para o de DISCIPLINA 1[...] É o que eu vejo[...] (SUJEITO B.1)

A primeira indagação quanto à estrutura do curso está voltada a questão de que no primeiro período os alunos compartilham muito pouco do saber físico com as disciplinas disponíveis para essa fase. $\mathrm{O}$ vínculo afetivo dos sujeitos com o saber físico permite aos mesmos projetar um maior desejo de aprofundar seus estudos e interesses a respeito desse saber em um curso de licenciatura em Física. Todavia, essa perspectiva parece não ter sido alcançada logo no primeiro semestre, fazendo com que os sujeitos concluam que é necessário um maior enfoque ao saber físico, em específico, para o despertar de seus aspectos motivacionais.

Analisando a grade curricular do curso, pudemos verificar que os saberes físicos são tratados de forma mais aprofundada somente na Disciplina 1. As Disciplinas 4 e 5 são voltadas 
para o trabalho dos saberes educacionais, enquanto a Disciplina 2 para os saberes matemáticos. Em especial, na fala do Sujeito B percebemos que essa pouca motivação para com as disciplinas 4 e 5 podem resultar em um decréscimo em seus níveis de autoeficácia e uma possível escolha por estratégias de aprendizagem diferentes daquelas empregadas nas demais disciplinas do curso.

Tal fato é de intrigante relação com a opção por um curso de graduação que busca a constituição de uma identidade docente por parte dos alunos. Para Dalri \& Mattos (2008) é de se esperar que o sujeito que opte por um curso de licenciatura estabeleça relações com as atividades da carreira docente, bem como, com os saberes que irá lecionar. Entretanto, a fala do Sujeito B, dispõe que seus elevados níveis de autoeficácia a respeito do saber físico, contribuíram de forma mais efetiva para a escolha da carreira e também de suas estratégias de aprendizagem do que os aspectos relacionados à prática docente. Assim, parece-nos que a falta de motivação do sujeito para com as Disciplinas 4 e 5 é resultante da busca pela aproximação do saber físico e a fuga do estabelecimento de sua identidade docente.

Apresentamos então os relatos de suas estratégias de aprendizagem, em vista do cenário descrito, como podemos observar no extrato, a seguir:

\begin{abstract}
Talvez eu faltasse mais nessa disciplina do que na disciplina que envolva cálculos. Pois não vou dizer que é uma coisa que eu goste, "vou estudar para a DISCIPLINA 1". Não vou dizer que eu goste de Ler[...] Ler[...] Ler[...] Ler[...] Como ele [o professor] só passa artigos[...] Não gosto de ficar duas ou três horas lendo artigos para estudar para uma prova. Prefiro ver uma vídeo-aula. (SUJEITO B.1)
\end{abstract}

É interessante notar que essa busca pelo saber físico norteia as estratégias de aprendizagem dos sujeitos. Quando o Sujeito B, afirma que possivelmente "faltasse" as disciplinas do curso que envolvesse mais as temáticas ligadas a licenciatura e a prática docente, o aluno apresenta uma estratégia que possivelmente não possibilitará o pleno desenvolvimento de um futuro professor atuante na Educação Básica. Essa dimensão parece entrar, por vezes, em contradição com a escolha dos sujeitos em um curso de licenciatura.

Como já descrito, anteriormente, a Disciplina 1 é a única destinada ao saber físico no primeiro período do curso. Contudo, as escolhas didático-metodológicas apresentadas nessa disciplina parecem não possibilitar ao Sujeito B a busca por estratégias de aprendizagem que o permitam se aproximar desse saber, dando maior atenção aquelas que envolvam os saberes matemáticos. Para Bandura (1997) os sujeitos irão se dedicar as atividades em que demonstrem possuírem maiores níveis de autoeficácia, sendo assim, e já identificado que os níveis de autoeficácia dos participantes do estudo foram construídos no processo de ensino e aprendizagem de Física na Educação Básica, fica evidente a escolha por estratégias de aprendizagem mais efetivas ligadas aos saberes matemáticos. De acordo com Pietrocola (2005) nas aulas de Física, os alunos aguardam o momento que todas as fórmulas e cálculos ganharão sentido para eles no mundo real. Assim, é de se considerar uma perspectiva de um ensino de Física, ainda na etapa do Ensino Médio, voltado exclusivamente para o desenvolvimento de habilidades matemáticas.

Contudo, a questão de deixar de lado, ou apresentar estratégias de aprendizagem diversas a respeito das disciplinas voltadas aos saberes educacionais estão intimamente relacionadas com a constituição da identidade docente desses sujeitos. Por isso, indagamos aos sujeitos, como eles vislumbram o fato de tornar-se professor. As respostas obtidas são apresentadas, a seguir:

Assumir a função de professor, ou tentar uma especialização em Astrofísica[...] Eu fico um pouco na dúvida porque eu gosto da sala de aula[...] Do ambiente da sala de aula[...] Eu acho interessante o professor estar lá explicando algo para alguém, tentar fazer alguém entender alguma coisa. (SUJEITO A.1)

Eu tenho um defeito[...] Eu me irrito facilmente[...] Exemplo, tipo, eu estou explicando e o aluno não está pegando tão facilmente, eu não tenho essa 
paciência de estar tentando, tentando e tentando[...] Eu acho[...] Eu acho não[...] Tenho certeza que esse é um grande empecilho em um curso de licenciatura. Acho que as cadeiras de DISCIPLINA 4 e de DISCIPLINA 5 servem para você trabalhar essa parte humana. Porque não é só ensinar física. (SUJEITO B.1)

De início muita gente não tem aquele desejo de ser professor. Mas assim[...] Quando eu apresento seminário e tal[...] Eu acho interessante você passar o seu conhecimento[...] Eu acho isso muito interessante. (SUJEITO C.1)

Sim, quero. Estou com uma vontade maior. Por conta dos trabalhos em grupo, das apresentações ajudou bastante. Dá um ânimo as apresentações e tal que a gente faz (SUJEITO C.2)

Dos extratos anteriores, podemos notar uma espécie de incerteza apresentada pelos sujeitos a respeito do desejo de atuar como professor. Possivelmente, esse estado de incerteza dos sujeitos justifica as suas primeiras impressões com relação ao curso e de uma provável desmotivação em seu início por não estarem tão imersos no saber físico quanto esperavam. Entretanto, chamamos a atenção para a fala do Sujeito C que, em momentos distintos das entrevistas, revela e afirma o seu desejo em se tornar professor da disciplina de Física. A realização das entrevistas em momentos diferentes do processo de ingresso desses sujeitos nos permitiu inferir que o reconhecimento da formação para o trabalho docente e o desejo de seguir a carreira pode ser um fator que norteia o comportamento desse indivíduo a partir de suas crenças de autoeficácia.

Sendo assim, aproveitemos esse momento de mudança de perspectiva do Sujeito C para apresentar suas primeiras impressões com relação ao curso:

No começo eu achei complicado. Na primeira semana[...] Na segunda semana[...] Eu fiquei desmotivado por que: "Será que é muito difícil?"[...] "Será que eu não vou conseguir?". Acho que essa é a dificuldade. (SUJEITO C.1)

Quando eu entrei tem aquele baque né[...] Você entra e não tem a noção de como é[...] "A Física é muito difícil"[...] "Você é louco de ir fazer Física"[...] Tem esse preconceito que fica enraizado um pouco[...] Daqui eu ouvi que tem algumas matérias que são bem complicadas também[...] Tem algumas que são complicadas[...] Então eu espero que até chegar lá [próximo período] eu tenha adquirido um conhecimento maior. (SUJEITO C.1)

Os extratos anteriores deixam transparecer um suposto estado de insegurança do aluno com relação ao início no curso. Do primeiro extrato, podemos perceber que ele chega a duvidar de sua capacidade quanto à possibilidade de cumprir com as atividades exigidas no curso. No segundo extrato, percebemos a construção de um cenário elaborado, a partir de persuasões verbais negativas (Bandura 1977) que remontam a dificuldade do curso estabelecido por sujeitos inseridos no cenário e também por aqueles que observam a realidade em uma posição mais distante. Para Pajares (1992) sujeitos com níveis mais baixos de autoeficácia são mais susceptíveis a persuasões verbais negativas inferindo diretamente sobre seus níveis de crenças de autoeficácia.

Esse cenário revela as impressões estabelecidas pelos sujeitos a respeito de seu ingresso no curso de licenciatura em Física. A descrição dessas falas é de fundamental importância para a compreensão da constituição dos níveis de autoeficácia desses sujeitos para que possamos relacioná-las com suas estratégias de aprendizagem e desempenho acadêmico nessa etapa de ingresso.

De acordo com Pajares \& Olaz (2008) os sujeitos que possuem elevados níveis de autoeficácia a respeito de sua capacidade para a realização de uma determinada tarefa, possuem uma maior resistência no enfrentamento dos obstáculos que possam surgir durante sua realização. Assim, buscamos melhor compreender quais foram às principais dificuldades vivenciadas pelos sujeitos em seu ingresso no curso de licenciatura e como eles lidaram com tais dificuldades. 
Durante a primeira fase de entrevistas, o Sujeito A nos revelou que a principal dificuldade encontrada no curso correspondia aos diferentes processos avaliativos evidenciados nas disciplinas do curso de licenciatura. Vejamos no extrato adiante:

\begin{abstract}
A primeira prova que eu fui fazer foi essa da DISCIPLINA 2[...] Aí eu fiquei nervosa e não consegui fazer[...] Dá um branco[...] Começa a tremer[...] E sei lá[...] "Talvez eu não consiga passar"[...] Eu ainda tentei responder[...] Fiquei assim rabiscando[...] Mas eu não consegui não[...] Então deixei para reposição[...] Aí eu já teria feito outras provas e estarei mais preparada[...] Em DISCIPLINA 1, que eu disse que sou muito nervosa para falar[...] Eu não consigo apresentar nem seminário e nem trabalho é a dificuldade que eu estou tendo. Teve dois seminários para apresentar até agora. O primeiro eu não consegui e o segundo eu só li mesmo[...] Eu fiquei nervosa e sai da sala[...] Entrei em pânico[...] Não conseguia falar[...] (SUJEITO A.1)
\end{abstract}

Para o Sujeito A o fato de realizar avaliações escritas ou apresentação de seminários causa certo desconforto. Percebemos que o fato de começar a tremer durante a execução de uma prova escrita, informa o sujeito por meio de uma das fontes de autoeficácia denominada de estados fisiológicos (Bandura 1977), sobre suas capacidades para participar daquela tarefa. Esse estado permite ao sujeito duvidar de suas capacidades, e por esse motivo abandonou a realização da atividade. $\mathrm{O}$ mesmo nos pareceu acontecer com a tarefa de apresentação de seminários, onde o sujeito informa que não conseguiu apresentar um deles e que no seguinte apenas leu o que tinha preparado. Por certo, um decréscimo no nível de autoeficácia do sujeito contribuiu para a escolha de tais comportamentos. Sendo assim, em um segundo momento da entrevista, perguntamos ao Sujeito A, como lidou com as atividades avaliativas durante o curso, a resposta obtida segue:

A prova já estou assim[...] Melhorzinha para fazer[...] Ainda dá um nervosismo, mas eu me acalmo depois. As primeiras provas ainda está meio complicado[...] (SUJEITO A.2)

Eu não superei não[...] Tive uma apresentação quinta-feira passada[...] Eu consegui falar[...] Eu ainda não superei completamente, mas eu estou melhorando. Consegui apresentar o seminário[...] Eu penso que eu estou indo bem[...] Que eu preciso superar essas dificuldades[...] Que eu vou precisar para o resto da vida[...] Eu vou precisar falar em público. Eu tenho que conseguir falar na frente das pessoas. Como que eu vou conseguir arrumar emprego mais para frente, né?! Ser professora[...] (SUJEITO A.2)

Das falas anteriores, podemos perceber um processo, ainda que para o sujeito pareça ser de pouco resultado, de superação das dificuldades vivenciadas no primeiro semestre. A mudança de comportamento apresentado pelo sujeito, provavelmente estabelece relações com seus níveis de autoeficácia e, por conseguinte, com seu desempenho acadêmico. Tal correlação esta associada às estratégias de aprendizagem apresentadas pelo Sujeito A, já no segundo período. Essas estratégias resultam em uma persistência para o enfrentamento das situações consideradas desafiadoras pelo indivíduo como a realização de uma avaliação escrita ou apresentação de um seminário. De acordo com Azzi \& Polydoro (2006), quando os indivíduos demonstram acreditar que suas ações promoverão os resultados desejados, eles tendem a persistir frente a situações dificultosas, como aconteceu com o Sujeito A. Podemos perceber a conclusão dessa afirmativa na seguinte fala:

Estou melhor[...] A preguiça está indo embora já[...] Eu estou ficando mais esperta, assim[...] Acho que foi porque apareceu disciplina mais interessante ou, porque eu sai do emprego. Estava ficando muito cansada. Não tinha tempo para fazer nada. (SUJEITO A.2)

É interessante notar que quando o sujeito afirma: "Estou melhor" a conclusão de uma expectativa de resultado de seus comportamentos e estratégias de aprendizagem realimentam 
seus níveis de autoeficácia o que permite ao indivíduo traçar diferentes estratégias para superar as dificuldades encontradas durante o ingresso no curso. Para Bandura (2001) os indivíduos tendem a regular seus comportamentos a partir da expectativa do alcance de resultados positivos. Dessa forma, segundo o autor, a previsão de resultados proporciona o estabelecimento de comportamentos, nesse caso, de estratégias de aprendizagem que possibilitem um futuro de sucesso desejado por intermédio de um comportamento antecipatório. Tais expectativas de resultado estão diretamente relacionadas às crenças de autoeficácia dos sujeitos, pois, de acordo com Bandura (1986) os resultados esperados pelos sujeitos estão diretamente relacionados com aquilo que acreditam ser capazes de realizar.

Já para o Sujeito B, poucos foram os momentos descritos como dificultosos em seu ingresso no curso de licenciatura em Física. Todavia, foi possível identificar um relato de dificuldade apresentado durante a participação nas disciplinas do primeiro período:

\begin{abstract}
Ainda não[...] Só na parte de leitura, mas assim, como eu já tenho uma base do técnico estou mais preparado que a maioria que saiu do Ensino Médio direto para cá. Porque têm muitos na minha sala. Quem sai do Ensino Médio, de escola pública, direto para cá, é um choque muito grande. Um exemplo, a Matemática da escola pública, me desculpe, mas é como se fosse uma piada[...] Inglês[...] Todo mundo que estudou na escola pública sabe o verbo To Be[...] Em Português o professor diz, leia esse texto e responda as questões e pronto. Aqui a gente está tendo que ler, parar, analisar, interpretar, muitas coisas. Coisas que muita gente não tem facilidade[...] Eu particularmente tenho uma certa facilidade. Então, por isso eu não enfrentei grandes dificuldades aqui. (SUJEITO B.1)
\end{abstract}

O Sujeito B parece apresentar um elevado nível de autoeficácia a respeito de seu desempenho acadêmico no curso. Ainda que ele faça menção ao fato da leitura de textos ser um processo que lhe causou o enfrentamento de certas dificuldades no primeiro período, o aluno evidencia, por meio de uma comparação com os demais colegas de turma, que as dificuldades elencadas ainda eram poucas em comparação com os alunos ingressantes. Esse fato se dá, conforme Pajares \& Olaz (2008), por um processo de subestimação causado pelo alto nível de autoeficácia do Sujeito B. Para os autores, indivíduos que possuem elevados níveis de autoeficácia, tendem a subestimar situações que são consideradas dificultosas por crerem em suas capacidades para o enfrentamento das mesmas.

Nesse sentido perguntamos ao Sujeito B, quais foram suas estratégias para superar a dificuldade advinda das atividades que solicitavam a leitura de textos. A resposta obtida foi:

\footnotetext{
É o que todo mundo fala[...] Se a gente veio para o curso de Física, a gente espera as exatas. $\mathrm{O}$ que muita gente procura é exatamente por isso[...] Mas a gente sabe que é uma licenciatura e tem todo esse cronograma a ser seguido[...] Mas a gente espera mais um pouco de exatas[...] E é assim, não é que eu me motive a estudar, gostando. Eu não vou sentar para ler um artigo de 55 páginas para fazer um fichamento. Não vou dizer que eu gosto[...] Eu faço[...] Eu leio[...] Eu entendo[...] Mas eu não vou fazer com aquela vontade que eu tenho para estudar para cálculo. (SUJEITO B.2)
}

O extrato anterior reforça nossa expectativa de pouca motivação por parte do sujeito para participar das atividades que envolvam a leitura de textos. Contudo, o aluno revela que apesar desse baixo estado de ânimo, faz uso de estratégias, como o fato de assistir vídeo-aulas para auxiliar no cumprimento das tarefas, já que o aluno afirma não ler os textos em sua completude. De acordo com Souza (2010), os fatores motivacionais associados às crenças de autoeficácia dos estudantes estão relacionados à escolha de suas estratégias de aprendizagem. Para a autora, os indivíduos que possuem autocrencas a respeito de suas expectativas de desempenho tendem a dedicar maior esforço para a escolha de estratégias de aprendizagem mais adequadas para o cumprimento das tarefas solicitadas. Como já retratado, o Sujeito B parece não despertar um estado motivacional em elevada escala para atividades que envolvam 
leitura, por esse motivo, a escolha por estratégias de aprendizagem, possivelmente, menos adequadas para a solução dessas atividades.

Para esse cenário vemos o cumprimento das regras do Contrato Didático (Brousseau 1986) que, não necessariamente, permitem uma maior aproximação com o saber, mas sim que visam à manutenção de um contrato vigente. Para Rocha (2017) os sujeitos que possuem elevados níveis de autoeficácia, reconhecem e lidam melhor com as regras estabelecidas pelo Contrato Didático, o que os permitem apresentar diferentes estratégias de aprendizagem dentro de um cenário de manutenção desse contrato.

Chama-nos a atenção o fato de o Sujeito B fazer referência a atividades que não envolvem leitura, mas sim a cálculos. Curiosos para compreender quais suas estratégias de aprendizagem para esse cenário, indagamos ao aluno quais são os comportamentos apresentados para estudo para essas disciplinas em específico. Segundo Sujeito B:

Acho que para cálculo não tem segredo, é sentar e estudar. Tem disciplinas, que você pesquisa os temas, assiste vídeo-aulas e você tem o conhecimento. Mas a questão da DISCIPLINA 6, você tem que estudar, não tem muito o que inventar. Não tem como traçar outra rota. (SUJEITO B.2)

Do extrato anterior, percebemos uma mudança de estratégia de aprendizagem quando as temáticas em evidência fogem da perspectiva da leitura e passam para o cenário no qual os cálculos tomam o papel principal. Segundo o Sujeito B, nas disciplinas que envolvem cálculos a principal estratégia de aprendizagem não é mais a de assistir vídeo-aulas, mas sim de estudar a partir da resolução de exercícios e atividades solicitadas. Essa mudança de estratégia é de interessante aspecto, pois permite ao sujeito identificar suas possíveis capacidades para participar das diferentes relações didáticas estabelecidas por cada uma das disciplinas presentes no primeiro ano de ingresso. Poderíamos pensar que a escolha de tais estratégias está vinculada a um melhor desempenho nessas disciplinas o que acaba por resultar em diferentes níveis de autoeficácia dos sujeitos participantes do processo de ensino e aprendizagem.

Nesse cenário relacionando ao desempenho acadêmico, o Sujeito C nos apresenta suas principais dificuldades associadas às estratégias de aprendizagem elencadas durante o curso:

\footnotetext{
No iniciozinho. Por exemplo, DISCIPLINA 2[...] De início eu assustei um pouquinho com a matéria, mas agora já estou me adaptando. Por exemplo, pegar o assunto. Porque eu não estava acompanhando direito e agora já estou conseguindo pegar o ritmo. Ao longo das aulas eu fui[...] O professor nos foi orientando[...] Dando um auxílio[...] Aí eu fui conseguindo chegar no nível de conhecimento para me adaptar ao que eu não estava entendendo de primeira. Tive um estudo maior e já estou tendo uma noção já. (SUJEITO C.1)
}

Para o Sujeito C, o estreitamento de sua relação com os saberes dispostos na Disciplina 2 permitiram observar a superação das dificuldades vivenciadas a respeito de sua participação nas atividades didáticas promovidas pela disciplina em questão. $O$ processo de orientação estabelecido pelo docente e o sentimento de êxito na participação das atividades propostas propiciaram o sujeito o enfrentamento das dificuldades, o que provavelmente resultou em um incremento em seu nível de autoeficácia.

Podemos perceber esse fato quando o aluno, no segundo momento de entrevista, revelanos que após o primeiro período reprovou na Disciplina 2. Perguntamos então como ele encarou essa reprovação:

Assim, não deu[...] Agora é bola pra frente né. Se tivesse continuado talvez tivesse reprovado em duas e seria pior. (SUJEITO C.2)

De acordo com o Sujeito C, a escolha pela reprovação está embasada em uma dedicação maior que teve de dirigir as atividades da Disciplina 2. Aquela que vimos, anteriormente, que o sujeito demonstrou possuir maiores dificuldades. A princípio poderíamos pensar que esse 
suposto insucesso gerasse um decréscimo em seus níveis de autoeficácia. Contudo, parece-nos que seus níveis de autoeficácia não foram abalados por tal fato. Ao contrário, o acontecimento da aprovação na disciplina que apresentava maior dificuldade contribuiu consideravelmente para o seu nível de autoeficácia.

É interessante notar que esse mesmo cenário, também foi vivenciado pelo Sujeito A, conforme veremos no extrato a seguir, quando perguntamos como ela encarava a reprovação na Disciplina 3:

\begin{abstract}
Porque eu não iria estudar DISCIPLINA 3 por conta própria[...] Eu me senti aliviada[...] Eu estava nervosa por causa da final[...] Fiquei aliviada com a reprovação[...] Para mim é melhor pagar em outro semestre, do que pagar a final e correr o risco de ficar com a média baixa e ter o compromisso de estudar DISCIPLINA 3 depois por conta própria. Porque eu sei que eu não ia fazer isso. (SUJEITO A.2)
\end{abstract}

Antes de estabelecer uma análise a respeito da fala expressa anteriormente, gostaríamos de retomar um momento a priori, onde a mesma aluna nos revelou suas perspectivas a respeito de uma possível reprovação:

\begin{abstract}
Posso reprovar, mas se eu fizer de novo eu consigo[...] Eu tenho medo de reprovar[...] Eu nunca reprovei antes[...] Mas vai que eu reprove em alguma coisa, que eu tenha alguma dificuldade e eu não consiga passar eu vou reprovar. Mas eu não vejo como uma coisa tão ruim[...] Não é tão ruim para eu reprovar[...] É ruim porque vai ser um determinado tempo perdido né[...] Mas se eu realmente necessitar reprovar naquilo, se eu não estou entendendo nada[...] Para mim não vai fazer mal passar mais um tempo tendo que refazer tudo aquilo. (SUJEITO A.1)
\end{abstract}

Apesar da afirmativa de receio em reprovar em alguma disciplina no primeiro período do curso, a aluna parece lidar com a situação com certa naturalidade. Como algo que faça parte das atividades que possam ser desempenhadas em seu ingresso. Esse fato toma maior naturalidade na primeira fala apresentada, onde o processo de reprovação gerou um estado de alívio para a estudante. Vale notar, que a possibilidade de cursar a Disciplina 3 em um outro momento do curso, no segundo período das entrevistas, não parece fazer com que o Sujeito A duvide de suas capacidades para continuar fazendo parte do curso de licenciatura. Assim, poderíamos pensar que seus níveis de autoeficácia acabaram por sofrer maiores incrementos na passagem do primeiro para o segundo período do curso, permitindo assim o elencar de diferentes estratégias de aprendizagem para a superação das dificuldades vivenciadas.

\title{
Conclusões
}

A partir dos relatos dos participantes do estudo, pudemos observar como os julgamentos a respeito de suas capacidades para participar do primeiro ano de ingresso do curso de licenciatura em Física do GFP/UFCG corroboram para a escolha de seus comportamentos ligados as suas estratégias de aprendizagem, bem como de seu desempenho acadêmico.

Ficou evidente nos relatos descritos, na seção anterior, que um dos fatores motivacionais desses estudantes para o ingresso no curso de licenciatura em Física, estava associado a uma espécie de sentimento pelo saber físico presente na estrutura do curso acadêmico. Para Pinheiro (2003), a projeção de vínculos afetivos com relação aos saberes dispostos na Relação Didática, possibilita aos sujeitos estabelecer escolhas de preferência e de comportamentos destinados a manutenção desses vínculos. Desse modo, pudemos observar que a escolha pelo curso de licenciatura em Física estava mais voltada aos aspectos do tipo sentimento pelo saber físico, como já aponta Simões et al. (2014), muito mais do que pela expectativa do trabalho docente. Para Simões et al. (2016) os fatores que direcionam a escolha pela carreira dos futuros docentes em Física esta também associada a facilidade no ingresso nos cursos de licenciatura, em vista da 
baixa concorrência; a possibilidade de vínculo com uma instituição pública; e a chance de adentrar em um mercado de trabalho carente de profissionais.

Essa afirmativa é corroborada pelas falas dos sujeitos quando perguntados sobre as possibilidades do trabalho docente ao final do curso de graduação. Os extratos nos revelaram uma provável incerteza por parte dos alunos quanto ao trabalho nessa área. Contudo, essa expectativa parece ter sofrido uma ligeira modificação ao final do primeiro ano, quando analisamos as falas dos sujeitos, em especial, do Sujeito C, que revelou-nos o fato das atividades acadêmicas realizadas nesse primeiro período permitirem um despertar para a atuação na carreira docente. Para Franco (2019) é necessário a inserção de componentes curriculares introdutórios a Física nos cursos de licenciatura, com o objetivo de elevação dos níveis de autoeficácia dos sujeitos, como também de incentivo a identidade docente.

Os fatores de possibilidades e de incertezas, logo no ingresso do curso, contribuíram para o estabelecimento dos níveis de autoeficácia dos sujeitos e direcionaram suas estratégias de aprendizagem e desempenho acadêmico. Pudemos perceber que as experiências positivas (Bandura 1977), uma das fontes que alimentam as crenças de autoeficácia dos sujeitos, atuaram como incremento nos níveis de autoeficácia dos estudantes quando analisamos o relato das principais dificuldades vivenciadas. $\mathrm{O}$ resultado positivo das estratégias de aprendizagem desses estudantes para o enfrentamento dessas situações promoveu o estabelecimento de níveis mais elevados de autoeficácia deles, mesmo vivenciando situações que, pudemos julgar, a priori, como de insucesso. Referimo-nos, nesse caso, as reprovações relatadas pelos Sujeitos A e C. De acordo com Pajares \& Olaz (2008) os indivíduos que possuem crenças de autoeficácia não se deixam abalar por resultados negativos por confiar em suas capacidades.

Ao analisarmos os relatos dos estudantes, percebemos que o Sujeito B possuía níveis de autoeficácia mais elevados do que os demais colegas de estudo, logo no início de sua carreira acadêmica. Para esse indivíduo as estratégias de aprendizagem variavam em vista de seu interesse e julgamento de capacidade para lidar com as atividades acadêmicas solicitadas. Contudo, apesar dos diferentes enfoques dados as disciplinas, o sujeito relata um bom desempenho acadêmico no primeiro ano de ingresso. Tais estratégias e desempenho concordam com Bandura (1993), onde estudantes com níveis mais elevados de autoeficácia relacionados à suas capacidades de aprendizagem e de realizar com sucesso as atividades acadêmicas valorizam de forma positiva o seu desempenho.

Diferentemente do Sujeito B, os demais colegas de turma (Sujeito A e Sujeito C) revelaram receber persuasões verbais (Bandura 1977) negativas logo no ingresso do curso. De acordo com Bandura (1977) as persuasões verbais são uma série de estímulos verbais que informam ao sujeito sobre a sua capacidade de realizar uma determinada tarefa. Tais fontes, possivelmente contribuíram para o enfraquecimento dos níveis de autoeficácia desses sujeitos no primeiro período. Entretanto, percebemos que a representação sobre suas capacidades sofreu considerável incremento ao final do segundo período, após o reconhecimento de suas capacidades e elaboração de suas estratégias de aprendizagem.

Percebemos que os níveis de autoeficácia dos participantes desse estudo acabaram por se elevar ao final do primeiro ano de ingresso. Esse fato, é de importante relevância, pois estudos (Caprara et al. 1998; Usher \& Pajares 2008) já apontavam que os níveis de autoeficácia dos alunos tendem a diminuir conforme eles avançam nos diversos períodos, dos mais variados cursos de graduação. Assim, o acompanhamento longitudinal dos fatores que influem nos níveis de autoeficácia dos estudantes do curso de licenciatura em Física torna-se relevante para reconhecermos como tais fatores conduzem os processos de elaboração de seus julgamentos a respeito de suas capacidades, de modo a se traduzirem em comportamentos associados a suas estratégias de aprendizagem e de seu desempenho acadêmico.

\section{Agradecimentos}

Aos avaliadores pela revisão crítica que ajudou a melhorar o manuscrito. 


\section{Referências}

Azzi R.G. \& Polydoro S.A.J. (2006) Auto-eficácia proposta por Albert Bandura: algumas Discussões (p. 9-24). In: Azzi R.G. \& Polydoro S.A.J. (Eds) Auto-eficácia em diferentes contextos. Campinas: Alínea. 160 p.

Bandura A. (1977) Self-efficacy: toward a unifying theory of behavioral change. Psycological Review, 84(2): 191-215. https://doi.org/10.1037/0033-295X.84.2.191

Bandura A. (1986) Social foundations of thought and action: a social cognitive theory. Englewood Cliffs: Prentice hall. 617 p.

Bandura A. (1993) Perceived self-efficacy in cognitive development and functioning. Education Psychologist, 28(2): 117-148. https://doi.org/10.1207/s15326985ep2802_3

Bandura A. (1997) Self-efficacy: the exercise of control. New York: W. H. Freeman. 604 p.

Bandura A. (2001) Social Cognitive Theory: an agentic perspective. Annual Review of Psychology, 52: 01-26. https://doi.org/10.1146/annurev.psych.52.1.1

Bandura A. (2005) Evolution of social cognitive theory (p. 9-35). In: Smith K.G. \& Hitt M.A. (Eds). Great minds in management: The Process of Theory Development. New York: Oxford University Press. 600 p.

Brousseau G. (1986) Fondements et méthodes de la didactique des mathématiques. Recherches em Didactique des Mathématiques, 7(2): 33-115.

Caprara G.V., Scabini E., Barbaranelli C., Pastorelli C., Regalia C. \& Bandura A. (1998) Impact of Adolescents' Perceived Self-Regulatory Efficacy on Familial Communication and Antisocial Conduct. European Psychologist, 3(2): 125-132. https://doi.org/10.1027/1016-9040.3.2.125

Carberry A.R., Lee H.S. \& Ohland M.W. (2010) Measuring Engineering Design Self-Efficacy. Journal of Engineering Education, 99(1): 71-79. https://doi.org/10.1002/j.2168-9830.2010.tb01043.x

Chemers M.M., Hu L. \& Garcia B.F. (2001) Academic Self-Efficacy and First-Year College Student Performance and Adjustment. Journal of Educational Psychology, 93(1): 55-64. https://doi.org/10.1037/0022-0663.93.1.55

Custódio J.F.F. (2007) Explicando Explicações na Educação Cientifica: Domínio Cognitivo, Status Afetivo e Sentimento de Entendimento. Tese (Programa de Pós-Graduação em Educação Científica Tecnológica). Universidade Federal de Santa Catarina, Florianópolis, Santa Catarina.

Dalri J. \& Mattos C.R. (2008) Aspectos Afetivo-Cognitivos na Aprendizagem e Suas Influências na Escolha da Profissão de Professor de Física: um Exemplo. In: Encontro de Pesquisa em Ensino de Física. 11. Atas[...]. Curitiba: Sociedade Brasileira de Física.

Elias S.M. \& MacDonald S. (2007) Using Past Performance, Proxy Efficacy, and Academic SelfEfficacy to Predict College Performance. Journal of Applied Social Psychology, 37(11): 25182531. https://doi.org/10.1111/j.1559-1816.2007.00268.x

Franco B.V.E. (2019) Estudo sobre adoção de metodologias ativas para o enfrentamento da evasão no curso de Licenciatura em Física da UNIPAMPA. Dissertação (Programa de PósGraduação Mestrado Acadêmico em Ensino). Universidade Federal do Pampa, Bagé, Rio Grande do Sul.

Gore P.A.J. (2006) Academic Self-Efficacy as a Predictor of College Outcomes: Two Incremental Validity Studies. Journal of career assessment, 14(1): 92-115. https://doi.org/10.1177/1069072705281367

Guerreiro D.C. (2007) Integração e autoeficácia na formação superior na percepção de ingressantes: mudanças e relações. Dissertação (Programa de Pós-Graduação em Educação). Universidade de Campinas, Faculdade de Educação, Campinas, São Paulo.

Heidemann L.A., Giongo S.L. \& Moraes K.R.M. (2020) Evadir ou persistir? Uma disciplina introdutória centrada no fomento à persistência nos cursos de licenciatura em Física. Revista Brasileira de Ensino de Ciências e Matemática, 3(1): 160-188. https://doi.org/10.5335/rbecm.v3i1.10091 
Lindstrom C. \& Sharma M.D. (2011) Self-Efficacy of First Year University Physics Students: Do Gender and Prior Formal Instruction in Physics Matter? International Journal of Innovation in Science and Mathematics Education, 19(2): 1-19.

Ludke M. \& André M.E.D.A. (1986) Pesquisa em educação: abordagens qualitativas. São Paulo: E.P.U. 128 p.

Lynch D.J. (2010) Motivational beliefs and learning strategies as predictors of academic performance in college physics. College Student Journal, 44(4): 920-927.

Minayo M.C.S. (2010) Técnicas de pesquisa: entrevista como técnica privilegiada de comunicação (p. 261-297). In: Minayo M.C.S. (Ed.) O desafio do conhecimento: pesquisa qualitativa em saúde. São Paulo: Hucitec. 406 p.

Nissen J.M. (2016) Self-Efficacy state experiences in introductory physics: with implications for gender in physics. Thesis (Department of Physics and Astronomy). The University of Maine, Orono, Maine.

Pajares F. (1992) Teachers' beliefs and educational research: cleaning up a messy construct. Review of Educational Research, 62: 307-332. https://doi.org/10.3102/00346543062003307

Pajares F. (1996) Self-efficacy Beliefs in Academic Settings. Review of Educational Research, 66(4): 543-578. https://doi.org/10.3102/00346543066004543

Pajares F. \& Olaz F. (2008) Teoria Social cognitiva e auto-eficácia: uma visão geral (p. 97-114). In: Bandura A., Azzi R.G. \& Polydoro S. (Orgs). Teoria Social Cognitiva: Conceitos Básicos. Porto Alegre: Artmed. $176 \mathrm{p}$.

Pietrocola M. (2005) Construção e realidade: o papel do conhecimento físico no entendimento do mundo (p. 9-32). In: Pietrocola M. (Org.). Ensino de Física: conteúdo, metodologia e epistemologia em uma concepção integradora. Florianópolis: UFSC. 236 p.

Pinheiro T.F. (2003) Sentimentos de realidade, afetividade e cognição no ensino de ciências. Tese (Programa de Pós-Graduação em Educação do Centro de Ciências da Educação). Universidade Federal de Santa Catarina, Florianópolis, Santa Catarina.

Restuboget S.L.D., Florentino A.R. \& Garcia P.R.J.M. (2010) The mediating roles of career selfefficacy and career decidedness in the relationship between contextual support and persistence. Journal of Vocational Behavior, 77(2): 186-195. https://doi.org/10.1016/j.jvb.2010.06.005

Rocha D.M. (2017) Desempenho escolar na disciplina de Física: um estudo de caso sobre a relação entre as crenças de autoeficácia e o contrato didático. Tese (Programa de PósGraduação em Educação). Universidade de Campinas, Faculdade de Educação, Campinas, São Paulo.

Rocha D.M. \& Ricardo E.C. (2013) As crenças de autoeficácia de professores de Física: um instrumento para aferição das crenças de autoeficácia ligadas a Física Moderna e Contemporânea. Caderno Brasileiro de Ensino de Física, 31(2): 333-364. https://doi.org/10.5007/2175-7941.2014v31n2p333

Schunk D.H. (1991) Self-efficacy and academic motivation. Educational Psychologist, 26: 207231.

Silva F.R., Barros M.A., Laburú C.E. \& Santos L.C.A. (2011) Crenças de eficácia, motivação e a formação de professores de física. Caderno Brasileiro de Ensino de Física, 28(1): 214-228. https://doi.org/10.5007/2175-7941.2011v28n1p214

Simões B.S., Custódio J.F. \& Rezende Junior M.F. (2014) Crenças de autoeficácia e a escolha da carreira de professor de Física. Latin-American Journal of Physics Education, 8(3): 503-511.

Simões B.S., Custódio J.F. \& Rezende Junior M.F. (2016) Motivações de licenciandos para escolha da carreira de professor de Física. Revista Brasileira de Pesquisa em Educação em Ciências, 16(1): 77-107.

Souza L.F.N.I. (2010) Estratégias de aprendizagem e fatores motivacionais relacionados. Educar em Revista, 36: 95-107. https://doi.org/10.1590/S0104-40602010000100008

Usher E.L. \& Pajares F. (2008) Self-Efficacy for Self-Regulated Learning: A Validation Study. Educational and Psychological Measurement, 68(3): 443-463. https://doi.org/10.1177/0013164407308475 


\section{Autoeficácia e estratégias de aprendizagem}

Wood R.E. \& Bandura A. (1989) Social cognitive theory of organizational management. Academy of Management Review, 14(3): 361-384. https://doi.org/10.5465/amr.1989.4279067

Zajacova A., Lynch S.M. \& Espenshade T.J. (2005) Self-Efficacy, stress, andacademic sucess in college. Research in Higher Education, 46(6): 677-706.

https://doi.org/10.1007/s11162-004-4139-z 